\title{
It Finally Happened to Me
}

\section{Rutb Kannai, MD}

Hebrew University, Hadassah School of Medicine, Jerusalem, Israel
Conflicts of interest: author reports none.

\section{CORRESPONDING AUTHOR}

Ruth Kannai, MD

6B Apt. 2 Reuven St. Bet Shemesh Israel 99544

rkannai@gmail.com

\begin{abstract}
It finally happened to me: I was sued for malpractice by the family of a patient who had died suddenly. My inner turmoil in the aftermath of this traumatic event affected me deeply. While I was an experienced family doctor dedicated to patient-centered medicine, the event challenged my customary approach to my patients. I share three vignettes from my practice that describe my inner dialogue both "preprosecution" and "postprosecution" and explain how I acted in each case.
\end{abstract}

Ann Fam Med 2014;12:475-477. doi: 10.1370/afm.1667.

t finally happened to me. I was sued. A young man under my care died suddenly, and his family pressed charges against the organization where I worked. "Yes, your name appears on the suit, but you're not the one being sued," my lawyer explained. "Your medical license is not in danger, and neither is your pocket." But this didn't alleviate my embarrassment, shame, frustration, and grief. After all, I had been his primary doctor. I was shocked. More than that, I was incredulous: I always listened to my patients so carefully, explained everything at length, and made sure I understood their cultural backgrounds and specific health perspectives. How could this happen to me, of all people?!

A large part of my grief was, of course, for the untimely death of my patient and the horrible loss his wife and children suffered. At the same time, I admit that a lot of my mourning was actually for myself: for my lost innocence, for the loss of what I had always seen as the holy encounter between doctor and patient. I knew it would never be the same again.

I found myself waking up many times at night from fitful sleep ${ }_{i}$ I was not finding pleasure in the usual joys of life. One thought was overwhelming all others: you're not good enough; you continually make mistakes; you'll just continue to make mistakes throughout the rest of your career. You have no control over your patients' lives; you're unworthy....

Only when the malpractice claim was settled outside of court was I able to diagnose myself as suffering from posttraumatic stress disorder: the sleeplessness, bad dreams, flashbacks, intrusive thoughts, and avoidance of similar situations were all indicative of my having suffered a traumatic event, particularly since they were not waning over time. I eventually realized that suppressing and denying these symptoms was undermining my emotional resilience, and I sought professional support.

I always teach interns that good communication with patients is not just a matter of politeness or an expression of our common humanity; it also helps inform the diagnosis and prevents harm by reducing unnecessary tests and potentially dangerous procedures. Now I add to my regular speech, with a sigh, that it helps enhance trust between the doctor and the patient and reduces the chances of prosecution for malpractice.

It is often noted that doctors practice "defensive medicine" to avert malpractice suits. I know I started down that path after the prosecution. I can't help being afraid of being sued again. When I reflect on my work since the prosecution, however, I see that defensiveness made me a bad doctor. Three examples:

Michal enters my office. She is 45 , and over the past few months she has visited the emergency room dozens of times. She has attacks of 
heart palpitations, a sense of choking, tingling in the hands, shortness of breath, and dizziness. During these attacks she feels she is "about to die." She is constantly anxious about the next attack, and this fear severely impairs her functioning both at work and at home. She has already completed a stress test, spirometry, and gastroscopy. A neurologist referred her for a head CT, a Doppler test, and an EMG. A cardiologist referred her for echocardiography and Holter monitoring, and during one of her hospitalizations she underwent a catheterization that found small-vessel disease. The gastroenterologist diagnosed gastroesophageal reflux, prescribed omeprazole, and referred her for an abdominal CT, which showed an unclear finding in the adrenal gland and a fatty liver. She now has appointments for annual follow-up CTs, an appointment at a liver clinic, appointments for meetings with a cardiologist and a neurologist, and an appointment for vestibular tests. In addition to the omeprazole, she is armed with aspirin, antacids, a statin for a goal LDL level lower than $70 \mathrm{mg} / \mathrm{dL}$, and medication for dizziness.

But I know what she is suffering from. The description she gave at her very first visit matched the diagnosis of panic disorder, a condition I know how to treat quite successfully.

The Dr Kannai I know from before the prosecution would gently place her hand on Michal's arm and tell her, Michal dear, I understand what you're going through. The symptoms you're describing are common to 1 of every 4 or 5 people and express an overload of the adrenergic system with hormones that induce the "fight or flight" response. After we rule out other reasonable causes for the symptoms you're describing, we can be quite optimistic and say that you are suffering from something that responds well to SSRIs and cognitive-behavioral therapy. It is quite likely that if you take this medication, the symptoms will either subside or at least be significantly reduced.

The postprosecution Dr Kannai, however, silently and shamefully mumbles to herself, "Why should I take this risk? After all, her father has heart problems, and her neighbor who complained of dizziness eventually discovered she had a brain tumor..." The postprosecution Dr Kannai thinks of every possible diagnosis for every symptom presented. She notes that perhaps she should add to the long list of tests Michal has already had. She should add a lumbar puncture, a bone marrow biopsy, and an MRI of the brain and cervical spine. The postprosecution Dr Kannai cannot allow herself to leave any stone unturned, even though she is an experienced clinician who has known Michal and her family for over 20 years. She knows that a true family doctor would now take the time to encourage, give strength, and offer treatment. She would hope for the best. But now, she has joined the cadre of doctors who protect themselves at the cost of their patient's genuine care.

When a mother enters my office with her smiling, 9-month-old baby, his pink cheeks adorned with congealed mucus after 2 days of fever, I know what to do. An inner smile arises when I recall the large, mustached director of the children's department where I studied. In the thunderous bass voice that concealed his soft, compassionate heart, he had said, "By the time you finish your rounds in the pediatric department, I expect you to be able to say confidently at the beginning of the physical exam, 'the child looks fine' or 'the child looks sick.' Once you can do that, you're halfway to a diagnosis and a work plan."

This baby definitely "looks fine"; he is smiling, willing to play, and breathing effortlessly. The remaining physical exam indicates a viral upper respiratory tract infection that will probably pass by itself. The mother smiles and nods in agreement with my explanation. In the past, I would have concluded the visit with this experienced mother of three with the following words, "It seems that in a few days your son will bounce back to being his cheerful self; if something changes, we're here for you." But my postprosecution persona is not satisfied with this and continues to explain in detail while furiously typing on the computer, "In case of increased fever, shortness of breath, discoloration, rash, apathetic behavior, restlessness or any other change of behavior, immediately return to the clinic, and if it's closed, to the emergency center or hospital." I proceed to provide the mother with a referral, just in case she should need to rush to the hospital.

I see dozens of such babies every week. However, a colleague of mine, an excellent pediatrician, recently sent home a child like this who 2 hours later broke out in a meningitis rash. The child lost consciousness upon arrival at the emergency room and died. This is every doctor's nightmare-and every mother's, too. Maybe I should tell the clinic director I'm willing to work only with children over 12 years old.

The third patient who reminds me of my humiliation nevertheless brings joy to my heart. Rose is 40 years old, warm hearted, and always ready with a smile. She works in a nearby day care center and has an infectious laugh and a hug for every child. Sometimes she will come in with a child who has fallen and gotten hurt on the playground. Before I even assess the situation, she will have soothed the child and alleviated his pain. Recently, though, I have seen her several times on her own account. A few months ago, she told me she is pregnant again. She already has 5 children but welcomes more, believing "every child brings his or her own blessing." She asked me then to conduct her "pregnancy supervision," but I had to decline. I had 
been told to respond that because of malpractice suits against family doctors who managed pregnancy supervisions that ended badly; we were ordered to avoid these supervisions entirely. We were required to refer every pregnant woman, whether she had a high- or low-risk pregnancy, to the women's health center. Since this patient and I are friends and our communication is open and authentic, she understood my reservations. She asked if she could talk to me informally whenever she was offered an exam or when she was faced with a diagnostic or treatment dilemma.

The first crisis ensued shortly. Rose refused to have amniocentesis, despite her advanced age. She listened to the explanations given by her gynecologist, and even though she understood that the test was covered by her HMO, she decided she did not want to take it. She loves children and is willing to raise a child with Down syndrome, because "they are children who know how to return love." Rose's gynecologist had her sign what felt to her like a humiliating form. She said the gist of the form was that "despite understanding her doctor's explanations, and in stark opposition to the experts' advice, she is willing to undertake an unreasonable risk of giving birth to a child with Down syndrome or some other congenital birth defect, due to her lack of responsibility and lack of judgment." He had further added that she could not make any claims against him given her outrageous lack of caution. This was most likely not the precise wording of the document, but this was how she perceived it and how she relayed it to me. Once again she asked me to accompany her throughout her pregnancy as her family doctor, and once again I had to refuse. Risk management.

Still, we discussed her choices. We talked about whether there were any circumstances in which she would rather abort a fetus, and if so, what tests she should take to rule out such illnesses or possible defects.

Not much time passed before Rose once again arrived at our clinic. Sobbing, she was ushered into my room while flashing an apologetic smile at the patients waiting in the hallway-an emergency. She told me that she had had an ultrasound at 24 weeks and had been told there was an echogenic focus in the fetus's heart. She was therefore advised to undergo a fetal echocardiography and amniocentesis to determine whether the fetus has a chromosomal abnormality. Once again, she had asserted that she would not abort due to Down syndrome, although she had decided that she would not want to raise a child with a significant anatomical defect. She felt that the gynecologist "got mad at her"; he had suggested an immediate abortion, documenting this in her file in bold letters. "And what do you think?" she asked me.

Postprosecution Dr Kannai wanted to cry out, "Family doctors are not allowed to supervise pregnancies. Your gynecologist knows best. This is his field of expertise, and he wants to help avert any harm to you, your fetus, and your family." But I knew that her gynecologist must also be scarred by prosecutions or the fear of them. He had recommended an abortion based on a sonogram whose clinical implications were not clear. This just because his patient, in her audacity, prefers to forego amniocentesis and give birth to a baby who may have Down syndrome. I managed to regain my composure, offer her a hug, and compliment her on what a good mother she is. Afterwards, we formulated questions we both wanted to ask the experts in gynecology as well as look up in the medical literature. Together we phoned her gynecologist to ask what the chances are that a fetus with an "echogenic focus" will develop a serious heart defect. His clear-cut response: "Forget it, doctor, why take unnecessary risks?"

I realized then that an unpleasant mirror was being placed before me: We, the prosecuted doctors, are abandoning our most fundamental contract with our clients, which is to place them at the center, putting their needs before our own. We are required to be altruistic and if need be to sacrifice our own comfort and perhaps even our security for them. "Defensive medicine," on the other hand, sacrifices the patient's well-being for the emotional health and sound sleep of the doctor, sometimes at the cost of trying to shift the doctor's responsibility (and guilt and insomnia) to the patient.

Rose and I approached a different doctor, a specialist in obstetric ultrasounds. This doctor received her that very day and observed that her fetus looked healthy, as far as the ultrasound showed. A few months later Rose lovingly and gratefully presented an alert and curious baby for his first exam at my well baby clinic. That night I slept soundly. I had the sweet smile of Rose's baby in my heart and the joy of being myself again.

To read or post commentaries in response to this article, see it online at http://www.annfammed.org/content/12/5/475.

Key words: bioethics; legal liability; medical errors; primary care; physician-patient relations; patient-centered care;

Submitted January 12, 2014; submitted, revised, April 8, 2014; accepted April 18, 2014.

Acknowledgment: I thank Mrs Aya Alon for her assistance in reviewing and editing this manuscript. 